\title{
KAJIAN KARAKTERISTIK ARSITEKTUR KARYA TAN TJIANG AY
}

\section{STUDI KASUS: RUMAH TINGGAL DI BANDUNG}

\author{
Andrey Caesar Effendi ${ }^{1}$, Danang Harito Wibowo ${ }^{2}$ \\ Program Studi Arsitektur, Universitas Matana ${ }^{1,2}$
}

\begin{abstract}
Abstrak
Banyak media yang mempublikasikan karya-karya Tan Tjiang Ay. Namun tak banyak yang meneliti tentang gaya atau filosofi desain dari Tan Tjiang Ay secara dalam. Gaya desain karya-karya Tan Tjiang Ay mirip gaya desain arsitektur modern, walaupun dia sendiri tidak pernah menyebutkan seperti itu. Oleh karena itu, peneliti mendalami karakterisitk desain arsitektur rumah tinggal karya Tan Tjiang Ay. Metode penelitian bersifat kualitatif dengan melakukan kajian literatur, studi lapangan, hingga analisis arsitekturalnya dengan menggunakan beberapa contoh desain rumah tinggal karya Tan Tjiang Ay untuk mendapatkan kesimpulan yang lebih komprehensif. Hasil penelitian menunjukkah bahwa karakteristik arsitektur rumah tinggal karya Tan Tjiang Ay di Bandung lebih cenderung menggunakan pendekatan Arsitektur Modern.
\end{abstract}

Kata Kunci : rumah tinggal, arsitektur modern, tan tjiang ay, karakteristik, desain

\section{Abstract}

Many media has published Tan Tjiang Ay's works. But not many have examined the style or philosophy of design from the Tan Tjiang Ay deeply. This study became interesting, because Tan Tjiang Ay's design style resembled the style of modern architectural design, even though he never mentioned it by himself. Therefore, the researcher explored the characteristics of the architectural design of the house by Tan Tjiang Ay. This research method is qualitative approach, by conducting literature studies, field studies, and architectural analysis by using several examples of residential designs by Tan Tjiang Ay to get comprehensive conclusion. The results of the study indicate that the architectural characteristics of residential houses by Tan Tjiang Ay in Bandung are Modern Architecture style.

Keywords : residential houses, modern architecture, tan tjiang ay, characteristics, design

\section{Pendahuluan}

Tan Tjiang Ay adalah seorang arsitek yang jauh dari hal-hal yang sifatnya puitis dan filosofis (Maretta, 2014). la adalah arsitek yang dikenal dengan desain bangunan-bangunannya yang sederhana. la tidak mendesain rumah yang penuh ornamen dan pernak-pernik pemanis. Simpel dan tidak ingin "berteriak". Pertama kali yang ia pikirkan dalam memulai desain adalah mengetahui kehidupan yang akan dilakukan dalam bangunan itu. Jika arsitek bisa menjiwai kehidupan itu, maka desainnya akan bagus. 
Ketika berbicara tentang arsitektur, biasanya terbayang oleh kita adalah bentuk bangunannya. Padahal, di dalamnya "kosong". Sayangnya, beberapa majalah meliput bangunan beliau, namun hanya membahas tampilan luarnya saja (Tajudin, 2013).

Baginya kenyamanan menjadi hal utama. la menerapkan arsitektur tropis dengan pendekatan bangunan berpori dengan unsurunsur ruang terbuka, taman, dan selasar. la terinspirasi dari rumah tradisional sederhana yang hanya berdindingkan bilik bambu serta berlantaikan bilah bambu. Cahaya dan sirkulasi udara tetap dapat masuk lewat celah-celah lantai dan diding tersebut, sehingga ruang di dalamnya tetap terang dan nyaman. Dalam pengolahan ruang, ia selalu menerapkan kesederhanaan yang kaya akan spasial ruang. Kesederhanaan pada tiap rancangannya tidak membosankan dan kaku, justru bisa dibilang selalu mempunyai spirit yang diungkap lewat ambience di tiap ruang (Maretta, 2014).

la juga menekankan bahwa pada bangunan ada ruang intim, ruang dekat, ruang privat, dan ruang bersama. Kejelasan perancangan ruangruang itu tergambar dari dimensi-dimensi yang dipakai dalam perancangan. la berpendapat bahwa perancangan arsitektur seharusnya tidak menjadi satu rumah produksi untuk mengeluarkan solusi yang praktis tapi tidak menyeluruh, ataupun hanya menawarkan variasi yang diperlukan dari dinamika kehidupan di Indonesia (Darmatriaji, 2013).

Namun, Tan Tjiang Ay menolak jika bangunannya dianggap modern minimalis. Ia lebih suka menyebutnya sebagai "reduksionis". Mereduksi ornamen tak penting dan kembali ke unsur-unsur mendasar pada bangunan. Menurutnya yang paling mewah di dunia ini adalah unbuilt space, lahan yang tidak dibangun. Bangunan itu merusak, jadi buatlah kerusakan sesedikit mungkin. Dengan mereduksi tersebut, hampir sama dengan jargon yang di diungkapkan oleh Mies van der Rohe (1965) yaitu Less is More. Sekilas cara mendesainnya mengikuti gaya arsitektur modern, mengamalkan kredo Form Follows Function (Tajudin, 2013).

Tan Tjiang Ay lahir pada tanggal 30 Januari 1940 di Semarang. Awalnya ia belajar di ITB, lalu sempat pindah ke UNPAR, sampai akhirnya sekitar tahun 1960-an ia memutuskan untuk tidak melanjutkan studi dan memulai perjalanannya sendiri (Maretta, 2014). Beliau merasa skeptis dengan dunia pendidikan arsitektur di Indonesia, dan merasa hal ini perlu direvisi besar-besaran, mulai dari metoda pengajaran hingga kebaharuan ilmu yang diajarkan. Beliau nampak sedih ketika melanjutkan cerita mengenai sahabat lamanya itu. Walaupun sempat bersama-sama dalam pencarian, akan tetapi dunia akademis seolah memisahkan mereka (Darmatriaji, 2013).

Arsitektur Modern mulai muncul akhir abad 19 di Eropa dan terus berkembang hingga saat ini di berbagai daerah di dunia. Arsitektur modern lebih mengutamakan kesederhanaan bentuk dan meniadakan segala macam ornamen yang tidak fungsional. Arsitektur Modern juga biasa disebut sebagai Internasional Style setelah pameran arsitektur modern di Amerika pada tahun 1932 oleh Philip Johnson.

Dalam bukunya yang berjudul Towards a new Architecture, Le Corbusier memformulasikan prinsip-prinsip arsitektur modern yaitu dengan mengangkat massa bangunan dari tanah sehingga menjadi ruang transisi antara publik dan privat (pilotis), pengurangan pemakaian dinding-dinding pembatas tembok sehingga tercipta ruang yang lebih bebas (The free plan), tampak yang lebih bebas dari ornamenornamen (The free facade), penggunaan jendela-jendela yang berbentuk horizontal atau bisa di maknai dengan penggunaan jendelajendela besar untuk memasukkan ruang luar ke ruang dalam (The horizontal / big window), mengganti ruang hijau yang ada di bawah dibawa ke atas (Roof gardens). 
Louis Henry Sullivan dikenal sebagai pembaharu dalam arsitektur Amerika yang dikenal dengan prinsip Form Follow Functionnya. Pada awal abad ke-20, Form Follow Function sering digabungkan dengan modern architecture dan industial design. Sullivan terkenal dengan desain-desain bangunan pencakar langit yang mempunyai bentukbentuk platonic solid dan pemakaian ornamenornamen sebagai representasi prinsip Form Follow Function yang ia pegang.

\section{Metodologi}

Penelitian ini menggunakan metode kualitatif dalam mengkaji karakteristik arsitektur rumah tinggal karya Tan Tjiang Ay. Hasil dari penelitian lalu dirumuskan dalam sebuah gagasan pedoman desain (desain konseptual), yang terdiri dari: konsep dasar, program ruang, zoning ruang, studi massa dan penampilan bangunan.

Berdasarkan dari latar belakang yang ada dan setelah dilakukan kajian pustaka tentang Arsitektur Modern, dapat disimpulkan aspekaspek yang merupakan karakteristik arsitektur modern terlihat pada Tabel 1 berikut.

Tabel 1. Karakteristik Arsitektur Modern (Sumber: Effendi, 2018)

\begin{tabular}{|l|l|l|}
\hline Le Corbusier & Mies van der Rohe & Louis Sullivan \\
\hline Pilotis & Clarity & Fom Follows Function \\
\hline Free Plan & Simplicity & Mass Production \\
\hline Free Facade & Flowing Space & Reduce Omament \\
\hline Honizontal / Big Window & Industrial Material & Minimalisme \\
\hline Modulor & Industrial Standar Measurement & \\
\hline
\end{tabular}

\section{Hasil dan Pembahasan}

\section{A. Rumah Tinggal di Jl. Dukuh No.14 (Luas Lahan +- $580 \mathrm{~m}^{2}$ )}

Berada di kawasan permukiman di tengah kota Bandung, berdekatan dengan jalan besar Jl. Ahmad Yani dan Jl. R.E. Martadinata dengan penghuni: 3 keluarga dengan masing-masing 4 anggota keluarga (pekerja dan pelajar). 3 keluarga ini mempunyai hubungan saudara dan masih sering berkumpul bersama, walaupun begitu mereka masih membutuhkan ruang privatnya masing-masing yang dipisahkan menjadi 3 bangunan yang merupakan rumah bagi masing-masing keluarga. Penghuni setiap keluarga merupakan pekerja (orang tua) dan pelajar (anak-anak) sehingga 3 keluarga tersebut mempunyai kebutuhan yang hampir sama antara satu dan yang lainnya.

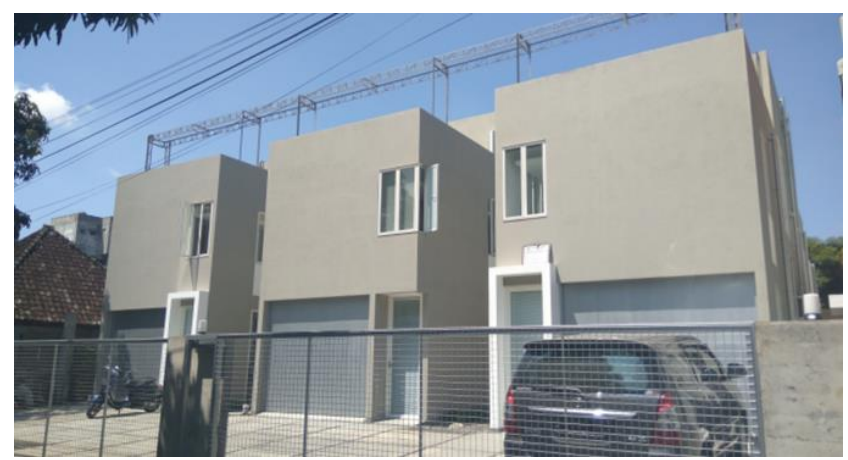

Gambar 1. Rumah Tinggal Jl. Dukuh (Sumber: Effendi, 2018)

\section{Pilotis}

Massa bangunan bagian belakang berfungsi sebagai ruang bersama penghuni dan ruang service dengan ruang bersama yang sebagian besar tanpa tembok masif agar ruang terlihat lebih menyatu dengan taman dan hanya di topang dengan kolom-kolom struktur. Bentukan massa ini menjadikan bentuk pilotis dengan mengangkat massa bangunan dengan memanfaatkan untuk kegiatan bersama. 

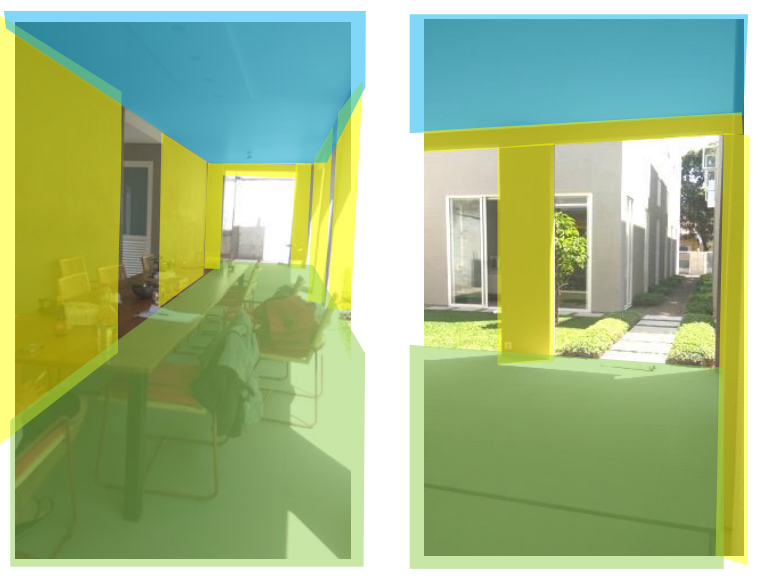

Gambar 2. Unsur Pilotis pada Rumah Jl. Dukuh (Sumber: Effendi, 2018)

\section{Free Façade and Ornaments}

Menurut Tan Tjiang Ay, permintaan klien yang terdiri dari tiga keluarga dalam satu site perumahan ini menginginkan kesan tertutup dari luar dan kesan terbuka di bagian dalam. Namun dengan penggunaan pagar transparan sehingga menyumbangkan city scape yang berbeda dengan lingkungan sekitarnya. Hampir di setiap desain arsitektur yang ia desain, Tan Tjiang Ay tidak menerapkan penggunaan ornamen pada bagian facade nya, terutama ornamen yang tidak memiliki fungsi.

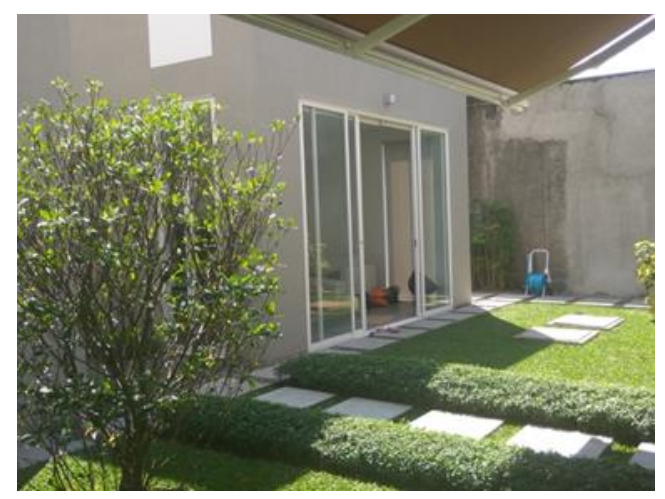

Gambar 2. Fasade dan Ornamen pada Rumah Jl. Dukuh (Sumber: Effendi, 2018)

\section{Big or Horizontal Window and Clarity}

Penggunaan jendela lebar yang mengarah ke taman di tengah bangunan / inner courtyard, membuat penghuni merasa lebih dekat pada alam karena adanya kesatuan secara 20 | Volume 2 Nomor 1 Agustus 2018 pandangan dengan taman di luar ruangan. Jendela lebar yang dapat dibuka juga memberikan kesan bahwa hampir tidak adanya pemisah antara ruang dalam dan ruang luar.

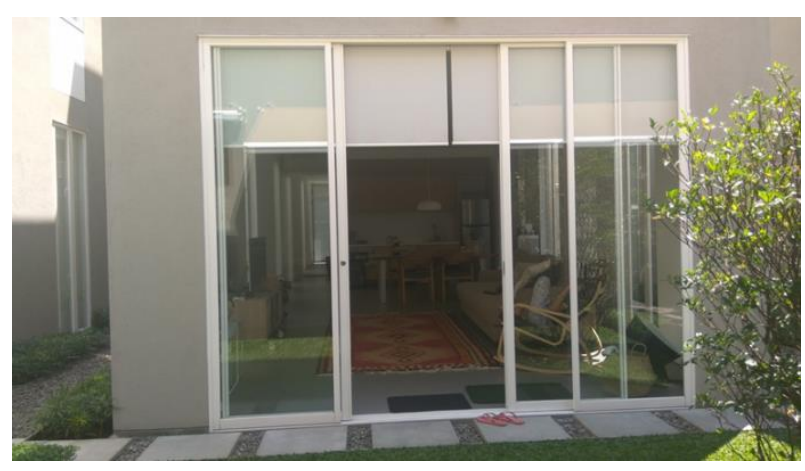

Gambar 4. Jendela dan Clarity pada Rumah Jl. Dukuh (Sumber: Effendi, 2018)

\section{Modular dan Industrial Standard Measurement}

Menurut Tan Tjiang Ay, patokan untuk mengatur massa bangunan adalah berdasarkan nalurinya sebagai arsitek. Sehingga setiap orang pasti bisa menghasilkan hasil yang berbedabeda. Bentuk bangunan menyesuaikan dengan bentuk lahan dan keadaan sekitar sekaligus menyumbang ruang arsitektural atau architectural space pada lingkungan. Salah satunya adalah penggunaan pagar transparan.

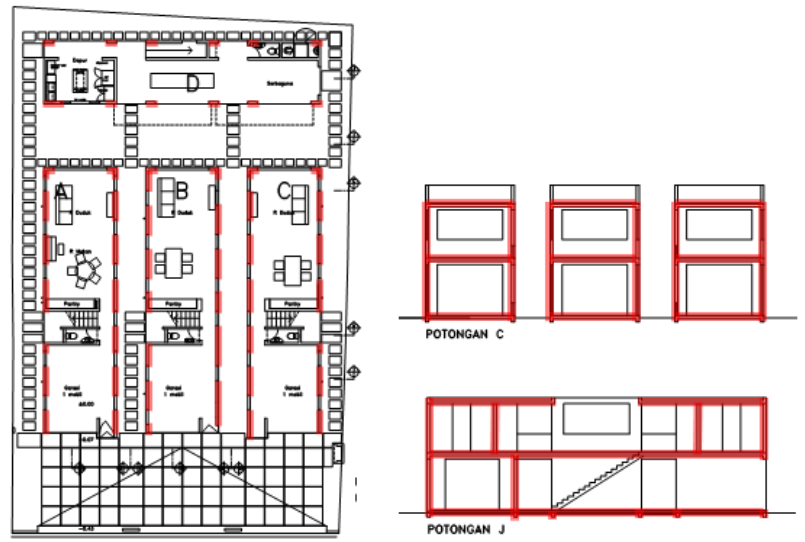

Gambar 5. Sistem Modular pada Rumah Jl. Dukuh (Sumber: Effendi, 2018)

Struktur dan konstruksi rumah ini sederhana karena terdiri dari satu grid saja dengan satu 
fungsi ruang. Massa bangunan dirancang tipis sehingga ruang dalam dapat langsung mengarah ke taman/ luar. Modul struktur yang cenderung sama memudahkan konstruksi yang dilakukan dan dapat membuat biaya yang lebih efisien.

Hanya sedikit kebutuhan ruang yang diperlukan penghuni sehingga kebutuhan luas bangunannya pun kecil dan juga agar dapat dihuni oleh 3 keluarga secara bersama-sama. Budaya keluarga yang menyukai suasana intim menjadikan ruang-ruang yang terbentuk mempunyai skala manusia yang intim. Salah satu ciri khas Tan Tjiang Ay yakni satu ruang satu fungsi satu grid dan langsung mengarah ke taman/luar/pemandangan.

\section{Industrial Material dan Mass Production}

Menurut TanTjiang Ay pada saat wawancara, pemilihan material yang digunakan adalah yang mudah ditemukan di lingkungan sekitar, diproduksi massal, cenderung awet, mudah perawatannya, dan sesuai fungsinya selain itu juga didiskusikan bersama klien. Untuk pemilihan material lantai, Tan Tjiang Ay memilih lantai keramik warna abu-abu dengan ukuran $40 \times 40 \mathrm{~cm} 2$ yang mudah ditemukan di pasaran, vinyl kayu untuk di kamar mandi, beton cetak, batu kerikil, dan rumput untuk di luar ruangan. Untuk material dinding, Tan Tjiang Ay memilih keramik dinding warna putih untuk area basah di kamar mandi, dinding ruang dalam menggunakan cat putih, pintu kayu dengan kusen dann jendela alumunium. Untuk bagian luar tembok di beri semen kamprot dan cat abu-abu, pipa pembuangan air menggunaka bahan metal, dan pepohonan perdu agar lingkungan lebih asri. Material atap menggunakan rangka baja ringan dengan atap metal dan plafon gipsum untuk ruang dalam. Selain itu desain Tan Tjiang Ay menggunakan atap berbahan terpal yang dapat dibuka dan ditutup sesuai keperluan pengguna.
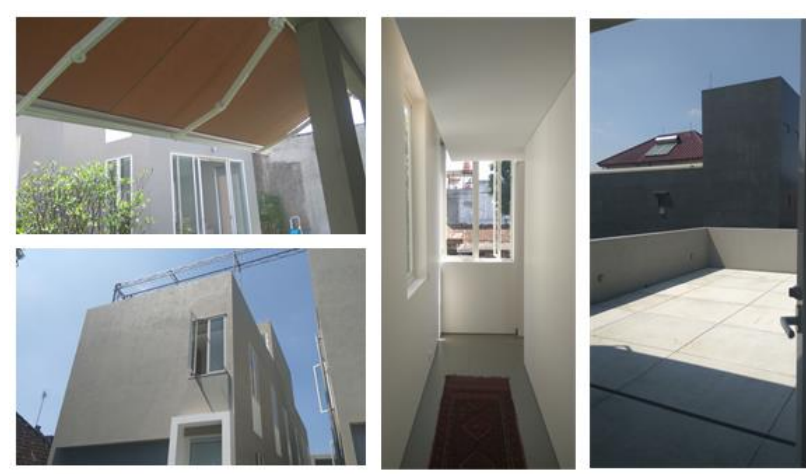

Gambar 6. Material pada Rumah Jl. Dukuh (Sumber: Effendi, 2018)

\section{Simplicity dan Minimalism}

Berdasarkan wawancara dengan Tan Tjiang Ay, unsur-unsur budaya dalam proses mendesain berasal dari klien yang tidak memiliki hubungan dengan lingkungan budayanya yakni Jawa Barat atau Sunda tetapi lebih bagaimana tiga keluarga hidup bersama dalam satu lahan, yang bisa jadi akan berbeda konteksnya dengan keluarga yang lain. Rumah dibuat menjadi 3 massa untuk masing-masing keluarga yang memiliki akses langsung ke jalan dan 1 massa untuk ruang bersama yang ada di bagian belakang site yang juga berfungsi sebagai area service bersama bagi ketiga keluarga.
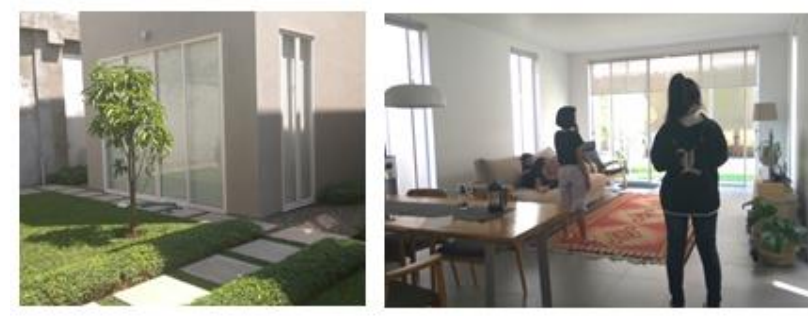

Gambar 7. Pendekatan Kesederhanaan pada Rumah Jl. Dukuh (Sumber: Effendi, 2018)

\section{Form Follow Functions}

Ruang-ruang yang ada di rumah $\mathrm{Jl}$ Dukuh ini dibuat sesuai dengan kebutuhan masingmasing keluarga walaupun setiap keluarga mempunyai kebutuhan yang tidak jauh berbeda, tidak lebih dan kurang. Bentuk ruang-ruang yang dibuat juga sederhana dan "jujur". 


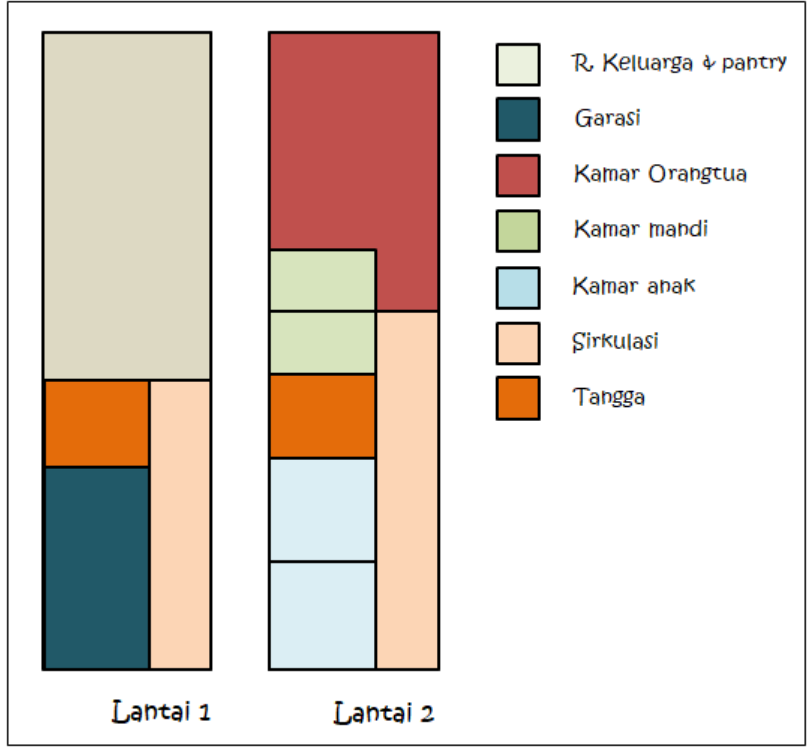

Gambar 8. Bentuk Ruang pada Rumah Jl. Dukuh (Sumber: Effendi, 2018)

Hirarki rumah ini berdasarkan kebutuhan klien yang terdiri dari tiga keluarga. Nilai, ukuran, dan posisi yang sama mencerminkan ketiga keluarga ini.

\section{Free Plan dan Flowing Space}

Ketiga massa yang berfungsi sebagai rumah tinggal tidak memiliki perbedaan yang signifikan karena kebutuhan masing-masing keluarga yang cenderung sama. Memasak, makan, tidur/istirahat, belajar (bagi anak), dan berkumpul bersama. Penghuni terdiri dari 3 keluarga yang sering berkumpul bersama, tetapi masih membutuhkan ruang privatnya masing-masing. Dalam merancang rumah ini, Tan Tjiang Ay berangkat dari kebutuhan dan aktivitas penghuni dalam rumah. Kemudian dari kebutuhan yang ada, beliau memberi solusi sekaligus usulan untuk penghuni rumah.

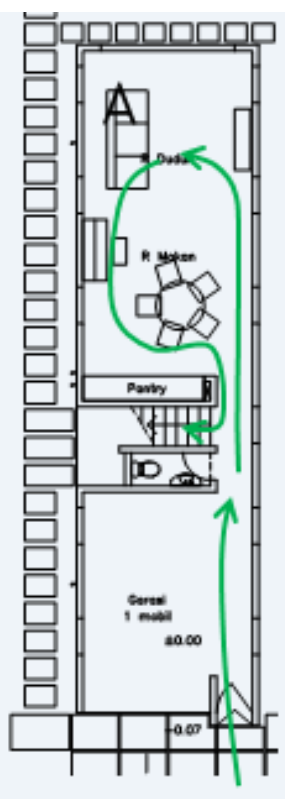

Lantai 1

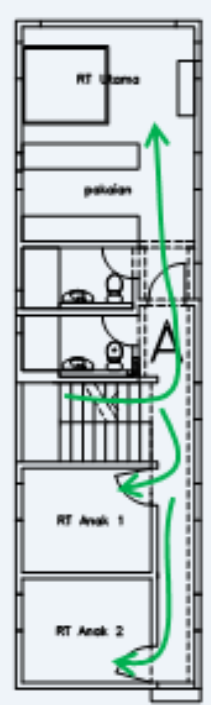

Lantai 2

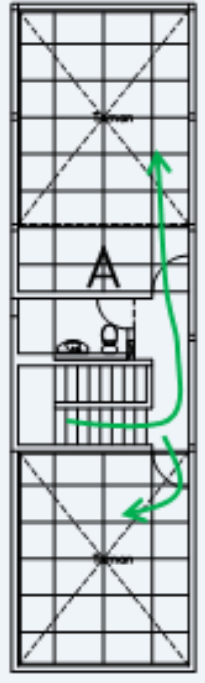

Lantai 3
Gambar 9. Sirkulasi Ruang pada Rumah Jl. Dukuh (Sumber: Effendi, 2018)

Berangkat dari kebutuhan serta aktivitas penghuni, desain rumah tinggal di Jl. Dukuh ini menghasilkan organisasi dan sirkulasi ruang yang berbentuk linear. Rumah ini dibuat menjadi tiga massa untuk masing-masing keluarga dan satu massa untuk bersama. Ide pemisahan massa ini juga merupakan pengaruh dari memori Tan Tjiang Ay yang pernah meninggali rumah budaya Cina dengan courtyard.

Orientasi bagian panjang bangunan mengarah ke sisi timur laut-barat daya. Bagian timur laut bangunan mendapatkan cahaya matahari pagi. Sedangkan radiasi sinar matahari siang dari bagian barat laut tidak terlalu menjadi masalah karena adanya bangunan tetangga yang lebih tinggi. Berdasarkan kebutuhan, dibuat juga bukaan yang saling berhadapan antara satu massa rumah dengan yang lainnya. Bukaan ini merupakan salah satu solusi yang cocok dengan penghuni rumah di Jl. Dukuh. 


\section{B. Rumah Tinggal di Jl. Umaia Raya, Dago, Ciumbuleuit (Luas Lahan 2000 m2)}

Berada di kawasan konservasi yang berkontur dan berbatasan langsung dengan Taman Hutan Raya Ir H. Juanda, Bandung. Penghuni adalah pasutri berumur 68 tahun (suami) dan 63 tahun (istri), yang menginginkan rumahnya sebagai ruang berkumpul bersama teman temannya (pengajian, bermain musik, dan makan bersama). Sehingga Tan Tjiang Ay meletakkan area privat yang tidak mempunyai akses langsung dari pintu utama.

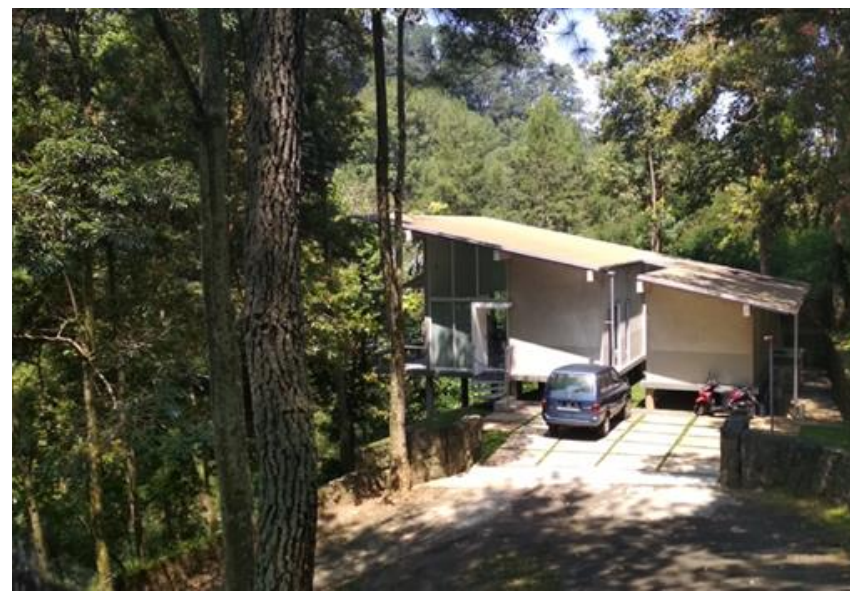

Gambar 10. Rumah Jl. Umaia Raya (Sumber: Effendi, 2018)

Menurut Tan Tjiang Ay pada wawancara, pengaturan massa bangunan dirumah ini berdasarkan tidak dimungkinkannya untuk membangun di sebagian besar lahan berkontur. Bentuk bangunan menyesuaikan dengan bentuk lahan \& keadaan sekitar yang berbatasan langsung dengan kawasan konservasi Taman Hutan Raya Ir H Juanda. Di mana arah bukaan diarahkan ke bukit dan pepohonan.

\section{Pilotis}

Massa bangunan pada rumah ini dibuat tidak menapak di tanah, tetapi sedikit diangkat dengan menggunakan kolom beton struktur dikarenakan lahan di daerah tersebut yang cenderung basah. Ruang kosong yang ada di bawah rumah dimanfaatkan untuk meletakkan instalasi pipa listrik dan tabung gas untuk keperluan di rumah tersebut.

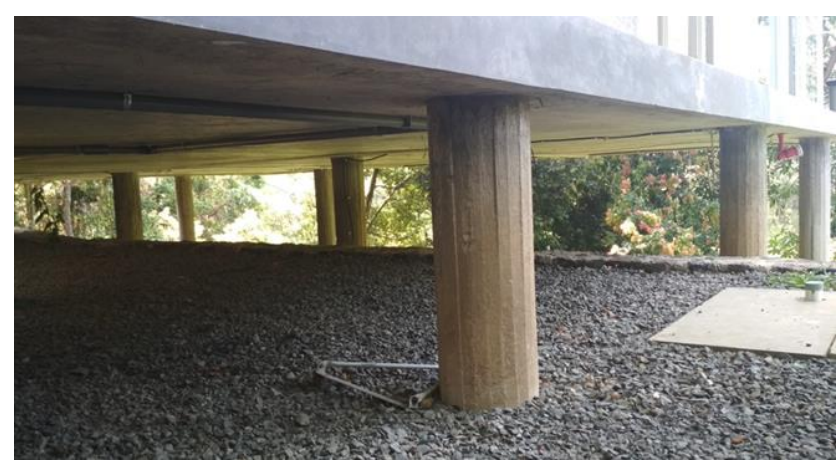

Gambar 11. Kolom Panggung pada Rumah Jl. Umaia Raya (Sumber: Effendi, 2018)

\section{Free Façade dan Ornaments}

Pada desain rumah di Jl Umaia Raya ini, klien menyerahkan sepenuhnya desain rumah tersebut kepada arsitek, maka Tan Tjiang Ay menggunakan fiolosfinya "Jika cukup hanya menggunakan satu garis mengapa harus dua garis" yaitu mereduksi ornamen-ornamen yang tidak mempunyai fungsi.

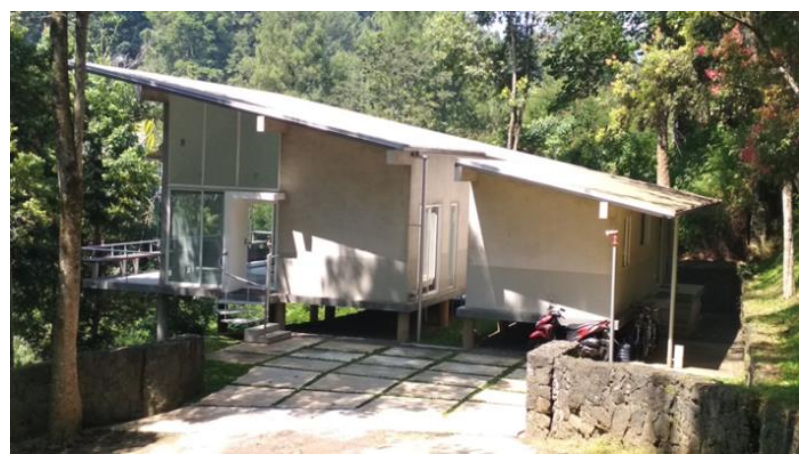

Gambar 12. Fasade pada Rumah Jl. Umaia Raya (Sumber: Effendi, 2018)

\section{Big or Horizontal Windows dan Clarity}

Penggunaan jendela lebar yang di letakkan di area Timur mengarah langsung ke view lembah sehingga selain mendapatkan cahaya matahari pagi rumah ini juga mendapat pemandangan langsung ke arah lembah yang diisi dengan pepohonan yang rindang. Jendela lebar yang dapat dibuka juga memberikan manfaat untuk menyatukan ruangan dalam dengan koridor 
luar sehingga mendapatkan area yang lebih besar yang sering difungsikan untuk kumpulkumpul arisan atau pengajian.

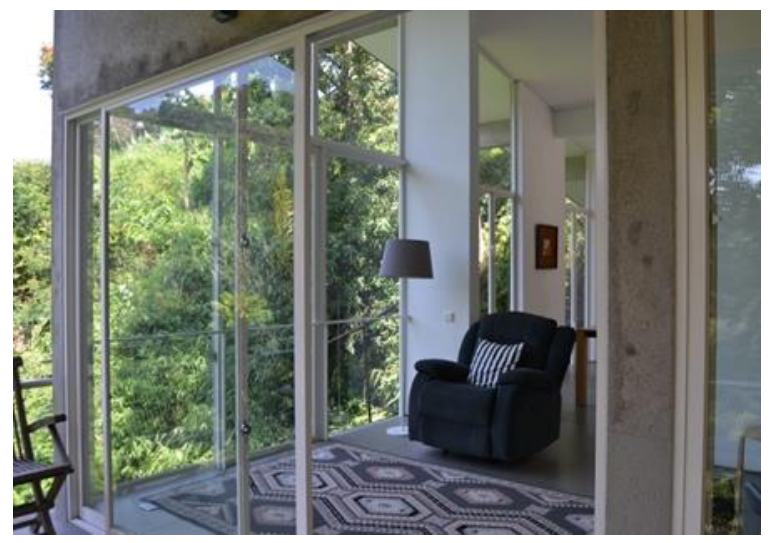

Gambar 13. Jendela pada Rumah Jl. Umaia Raya (Sumber: Effendi, 2018)

\section{Modular dan Industrial Standard Measurement}

Dengan menggunakan modul struktur yang cenderung sama yaitu $3 \mathrm{~m} \times 3 \mathrm{~m}$, rumah ini menggunakan struktur yang cenderung sederhana untuk memudahkan pembangunan di lahan berkontur. Luas area yang memudahkan untuk dibangun dan view yang cukup bagus ke arah lembah mempengaruhi bentuk dan orientasi bukaan dari masa bangunan tersebut.

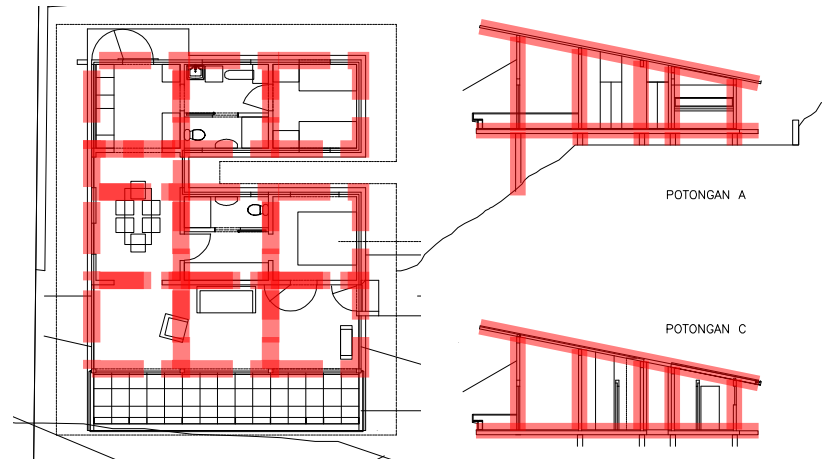

Gambar 14. Sistem Modular pada Rumah JI. Umaia Raya (Sumber: Effendi, 2018)

Dengan hanya ada 2 orang penghuni tetap, sepasang suami - istri dan cucu-cucu yang datang dan menginap di akhir pekan, maka hanya sedikit kebutuhan ruang yang diperlukan sehingga kebutuhan luas bangunannya pun tidak terlalu besar. Selain itu keluarga ini sering menjadikan rumah sebagai ruang berkumpul bersama teman-temannya (pengajian, bermain musik, dan makan bersama) menjadikan desain rumah ini berbeda dari rumah yang lainnya.

\section{Industrial Material dan Mass Production}

Dikarenakan letaknya yang berada di dataran tinggi dan mempunyai kelembaban yang cukup tinggi, jadi pemilihan material yang digunakan adalah bahan material yang cenderung awet, mudah perawatannya, diproduksi massal, dan sesuai fungsinya. Untuk pemilihan material lantai, Tan Tjiang Ay memilih lantai keramik warna abu-abu dengan ukuran $40 \times 40 \mathrm{~cm} 2$, beton cetak, batu kerikil, dan rumput untuk di luar ruangan. Untuk material dinding, Tan Tjiang Ay menggunakan keramik dinding warna putih untuk area basah di kamar mandi, dinding ruang dalam menggunakan cat putih, pintu kayu dengan kusen dann jendela alumunium. Untuk bagian luar tembok diberi kamprot dan penggunaan talang dan pipa pembuangan air menggunakan bahan metal. Material atap menggunakan atap metal spandex dengan rangka baja ringan dan plafon gypsum untuk ruang dalam. Selain itu Tan Tjiang Ay menggunakan atap berbahan terpal yang dapat dibuka dan ditutup sesuai keperluan pengguna.

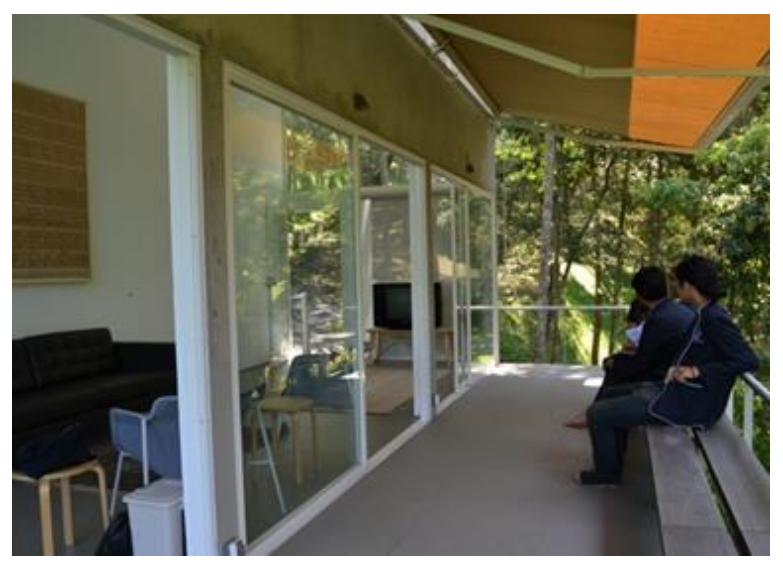

Gambar 15. Material pada Rumah JI. Umaia Raya (Sumber: Effendi, 2018) 


\section{Simplicity dan Minimalism}

Penyederhanaan bentuk layout berasal dari unsur-unsur budaya klien itu sendiri. Ruang keluarga yang hanya dibatasi dengan jendela kaca yang bisa dibuka dan berbatasan langsung dengan teras koridor yang luas berfungsi untuk menampung banyak tamu karena kebiasaan keluarga tersebut yang suka mengundang banyak tamu ke rumahnya.

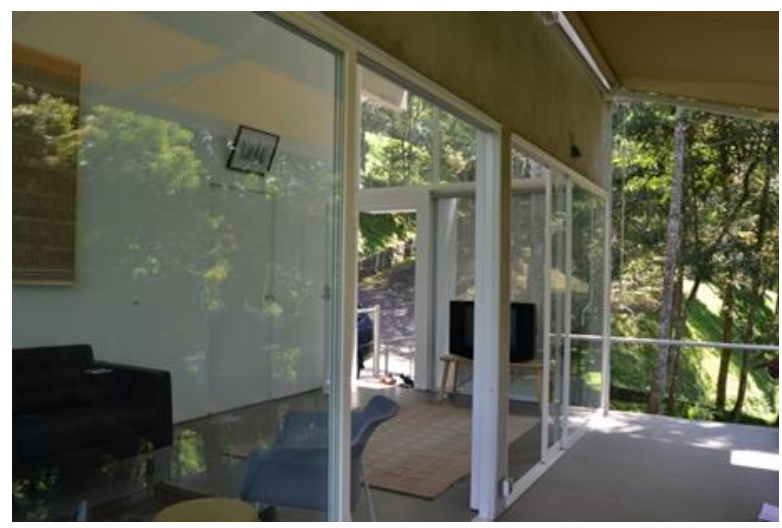

Gambar 16. Pendekatan Kesederhanaan pada Rumah Jl. Umaia Raya (Sumber: Effendi, 2018)

\section{Form Follow Functions}

Selain ruang tengah dan kamar utama, ada kamar yang diperuntukan untuk anak dan cucu yang datang setiap weekend atau kerabat lain yang menginap.

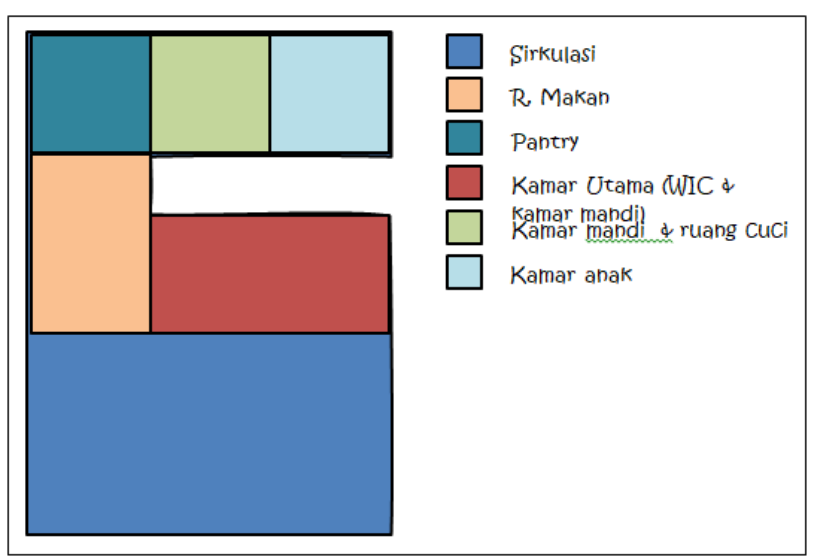

Gambar 17. Bentuk Ruang pada Rumah JI. Umaia Raya (Sumber: Effendi, 2018)

\section{Free Plan dan Flowing Space}

Berdasarkan dari kebutuhan serta aktivitas penghuni yang sering mengadakan acara bersama, maka pembatasan ruang hanya dilakukan pada ruang-ruang privat seperti kamar tidur dan kamar mandi. Ruang-ruang lainnya seperti teras, ruang keluarga, ruang makan, pantry, dan lainnya dibuat mengalir tanpa batas yang masif, sehingga dapat memberikan keleluasaan sirkulasi dan ruang pada saat banyak orang datang.

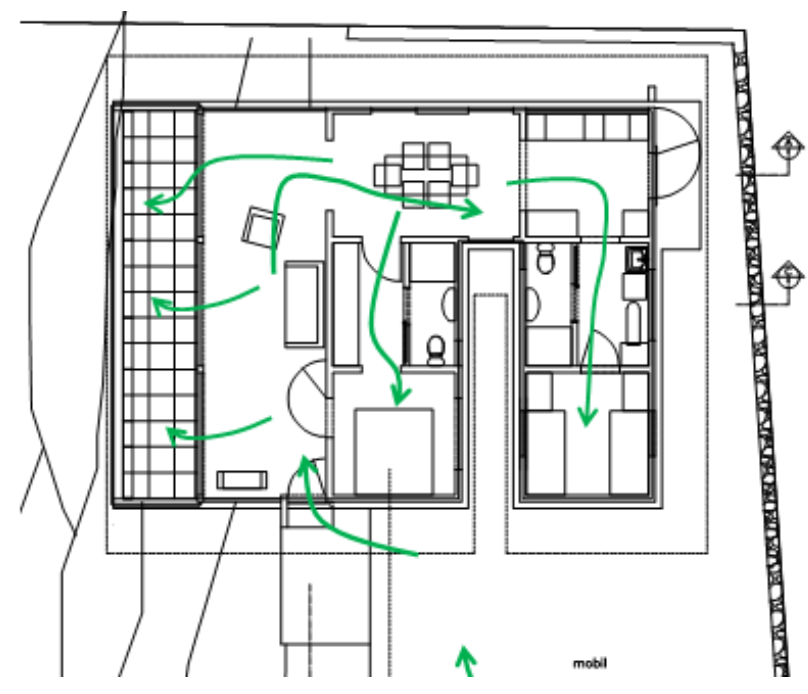

Gambar 18. Sirkulasi pada Rumah Jl. Umaia Raya (Sumber: Effendi, 2018)

Orientasi bukaan bangunan mengarah ke sisi timur - barat. Bagian timur bangunan mendapatkan cahaya matahari pagi. Bagian barat bangunan yang mendapatkan cahaya matahari sore terhalang oleh pepohonan di belakang rumah. Berdasarkan lokasi yang berada di tepi lembah dengan banyak pepohonan dibuatlah view ke arah tersebut sehingga membuat seperti adanya penyatuan ruang luar dan ruang dalam.

\section{Kesimpulan}

Penlitian ini telah mengkaji tentang karakteristik figural spasial karya arsitektur rumah tinggal yang di desain oleh Tan Tjiang Ay 
Kajian Karakteristik Arsitektur Karya Tan Tjiang Ay

berdasarkan paham Arsitektur Modern. Kajian ini dianalisa dan dijabarkan dengan menggunakan kajian karakteristik atau prinsipprinsip dalam Arsitektur Modern yang dibagi menjadi figural dan spasial.

Berdasarkan analisa akademik rinci yang telah dilakukan pada studi kasus tersebut, delapan dari sembilan (rincian dari 8 karakteristik) karakteristik, lihat Tabel 2, yang ada pada arsitektur modern terdapat pada karya arsitektur Tan Tjiang Ay tersebut yang sebenarnya sudah ada sejak tahun 1930an di Benua Eropa dimana paham Arsitektur Modern tumbuh dan berkembang sangat pesat dengan tokoh-tokohnya pada waktu itu.

Oleh sebab itu berdasarkan tabel di bawah ini, dapat disimpulkann bahwa karya-karya arsitektur rumah tinggal Tan Tjiang Ay tersebut berpijak pada paham Arsitektur Modern.

Tabel 2. Karakteristik Arsitektur Modern Rumah Tingga Tan Tjian Ay di Bandung (Sumber: Effendi, 2018)

\begin{tabular}{|l|c|c|}
\hline \multicolumn{1}{|c|}{ Karakteristik Arsitektur Modern } & Jalan Dukuh & Dago \\
\hline Pilotis & X & X \\
\hline Free Plan \& Flowing Space & $\checkmark$ & $\checkmark$ \\
\hline Free Façade \& Reduce Ornament & $\checkmark$ & $\checkmark$ \\
\hline Horizontal / Big Window \& Clarity & $\checkmark$ & $\checkmark$ \\
\hline Modulor \& Industrial Standar Measurement & $\checkmark$ & $\checkmark$ \\
\hline Simplicity \& Minimalisme & $\checkmark$ & $\checkmark$ \\
\hline Industrial Material \& Mass Production & $\checkmark$ & $\checkmark$ \\
\hline Form Follows Function & $\checkmark$ & $\checkmark$ \\
\hline
\end{tabular}

Dengan hasil kesimpulan ini diharapkan dapat menjadi masukan, pertimbangan, dan mungkin pedoman bagi para akademisi, pengamat, mahasiswa jurusan arsitektur dan peneliti sendiri yang juga sebagai praktisi arsitektur. Selain itu kajian ini diharapkan dapat menjadi inventaris sekaligus ensiklopedia karya Arsitektur Modern Indonesia.

\section{Daftar Pustaka}

Darmatiraji, Asa (2013). "Arsitektur \& Rumah di Indonesia". Jurnal Ruang edisi 7.
Corbusier, Le (1927). "Towards A New Architecture". Dover Publications, New York. Maretta, Nissa (2014). "Tan Tjiang Ay". Indesign Indonesia Vol. 072013.

Tajudin, Qaris (2013). "Sang Reduksionis". Tempo.

Van Der Rohe, Mies (1965). "Mies Van Der Rohe : The Art of Structure". Praeger, New York. 